\title{
Yeast One/Two-Hybrid System
}

National Cancer Institute

\section{Source}

National Cancer Institute. Yeast One/Two-Hybrid System. NCI Thesaurus. Code C18140.

Molecular biology technique used to identify interacting proteins in a yeast model. A protein of interest (the bait) is fused to the DNA-binding domain of a yeast transcription factor (usually GAL4). (Usually) a cDNA library is fused to the GAL4 activation domain. The library is then introduced into yeast cells carrying the bait construct. Functional interaction of the bait with fusion proteins from the library bring together the binding and activation domains of the transcription factor, allowing activation of a reporter gene. (syn: yeast two-hybrid system) (NCl/OSP) 